\title{
Mechanism of Bronchoconstriction Caused by Cigarette Smoking
}

\author{
G. M. STERLING,* M.B., B.CHIR., M.R.C.P.
}

Brit. med. 7., 1967, 3, 275-277

Inhalation of the smoke of a single cigarette causes brief bronchoconstriction in man (Zamel et al., 1963 ; Pelzer and Thomson, 1966), and it has been suggested that this is due to the irritant action of smoke particles on receptors in the tracheobronchial tree. Other possible mechanisms are the pharmacological activity of nicotine or gaseous products of combustion such as oxides of nitrogen, but it has been shown that neither varying the nicotine content of cigarettes nor removal of nitrous oxide from the smoke alters the bronchoconstrictor effect (Nadel and Comroe, 1961). Moreover, Widdicombe et al. (1962) have found that chemically inert carbon particles can cause bronchoconstriction in man and cats and that this effect can be blocked by atropine or by cooling the vagi, indicating that it is a reflex reaction mediated through the vagus. By analogy it has been assumed and stated that smoking in man works in the same way, but there is little direct evidence on this point, and the present study has been designed to investigate this assumption further, through observation of the effect of atropine on the bronchial reaction to cigarette smoke.

\section{Methods}

Cigarette smoke causes only slight bronchoconstriction, which is not usually detectable by standard spirometry, and a more sensitive method has therefore been used.

Airway resistance and lung volume were measured by means of a constant-volume whole-body plethysmograph of about 450 litres capacity, as described by DuBois et al. (1956). After waiting two or three minutes to allow the air in the plethysmograph to warm to a constant temperature, the subject panted shallowly through a heated flowmeter at two breaths a second, and the flow signal was fed into the vertical axis of a cathoderay oscilloscope, while a simultaneous plethysmograph pressure signal was fed into the horizontal axis to produce a flat vector loop. A shutter attached to the flowmeter and mouthpiece was then closed by a remotely controlled solenoid and the subject continued to make shallow panting movements against this obstruction, which enabled the lung volume at the natural panting level to be measured plethysmographically. This was called the thoracic gas volume (T.G.V.) and was used to correct airway resistance, since the latter normally varies inversely with lung volume (Briscoe and DuBois, 1958). Functional residual capacity (F.R.C.) was measured by instructing the subject to make panting movements after the shutter had been closed at the end of a normal slow expiration. The angles of the vector loops produced by these manœuvres were measured by alignment against a ruled Perspex disc which rotated within a fixed protractor scale in front of the oscilloscope screen. This method was initially checked against simultaneous photographic traces, and, after close agreement had been found, the latter more laborious method was abandoned.

Each test consisted of six or seven consecutive measurements of airway resistance and thoracic gas volume, of which the last five were used in the calculation of mean airway resistance in $\mathrm{cm} . \mathrm{H}_{2} \mathrm{O} /$ litre/second. From this value $0.45 \mathrm{~cm} . \mathrm{H}_{2} \mathrm{O} / 1$. $/ \mathrm{sec}$. was subtracted for the resistance of the flowmeter and mouthpiece, and the result was then converted to its reciprocal, airway conductance (C.A.), which has a more linear relation with lung * Research Registrar, Respiratory Department, St. George's Hospital,
London S.W.1. volume. Results were expressed as the ratio of airway conductance to thoracic gas volume (C.A./T.G.V.) to allow for changes in lung volume when comparing changes in airway resistance (Nadel and Comroe, 1961).

\section{Subjects}

Eleven normal adults, of whom three were non-smokers, were each tested on two occasions. On the first, C.A./T.G.V. was measured at rest and again two to three minutes after 15 inhalations over five minutes of a filter-tipped cigarette. On the second, C.A./T.G.V. was measured at rest, then 25 minutes after the subcutaneous injection of $1.2 \mathrm{mg}$. of atropine sulphate, and finally after inhalation of a cigarette as before. The twn studies were carried out at the same time of day, within a few days of one another, and care was taken to ensure that none of the subjects had smoked within two hours of the experiment, since the bronchoconstrictor effect of a cigarette may last up to 80 minutes (Nadel and Comroe, 1961).

\section{Results}

Lung Volumes

Lung volume was measured at both F.R.C. and natural panting volume (T.G.V.), and the results, with the one female subject excluded, are shown in Table I. It can be seen that T.G.V. is

TABLE I.-Lung Volumes (Litres) at Rest on Two Occasions in 10

\begin{tabular}{l|c|c|c|c|c|c} 
& \multicolumn{3}{c}{ Male Subjects } \\
\cline { 2 - 7 } Subject & \multicolumn{2}{|c|}{ Functional Residual Capacity } & \multicolumn{3}{|c}{$\begin{array}{c}\text { Thoracic Gas Volume } \\
\text { (= Panting Volume) }\end{array}$} \\
& 1 & 2 & Mean & 1 & 2 & Mean \\
\hline G.M.S. & 4.69 & 3.83 & 4.26 & 4.88 & 4.19 & 4.54 \\
R.H. & 2.90 & 3.11 & 3.00 & 3.54 & 3.64 & 3.59 \\
P.R. & 4.64 & 4.40 & 4.52 & 4.91 & 4.40 & 4.66 \\
J.H. & 3.10 & 2.94 & 3.02 & 4.12 & 4.26 & 4.19 \\
J.B. & 4.92 & 5.02 & 4.97 & 5.55 & 5.33 & 5.44 \\
P.L. & 4.16 & 4.24 & 4.20 & 4.67 & 4.74 & 4.71 \\
T.D. & 4.02 & 3.88 & 3.95 & 4.75 & 5.35 & 5.05 \\
J.C.B. & 4.05 & 3.91 & 3.98 & 4.80 & 4.61 & 4.71 \\
R.B. & 4.58 & 4.54 & 4.56 & 5.25 & 5.42 & 5.34 \\
C.L. & 3.44 & 3.16 & 3.30 & 4.19 & 3.51 & 3.85 \\
\hline Mean & & & $3.98 *$ & & & $4.61 *$ \\
\hline
\end{tabular}

Difference $=0.631$

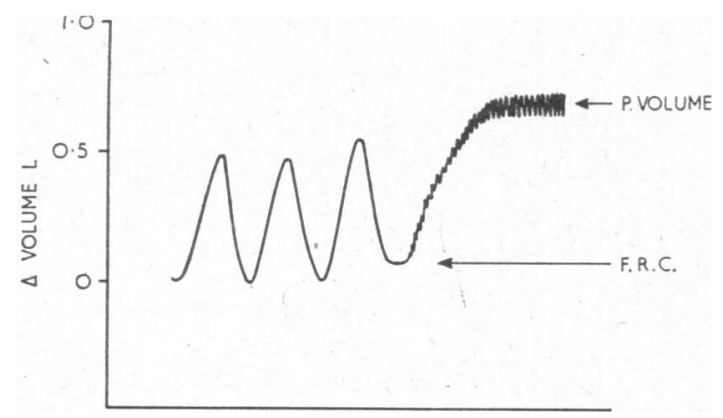

FIG. 1.-Lung volume change with onset of rapid shallow panting after three normal tidal breaths. (P.volume=

generally larger than F.R.C., as has been found previously (Nadel and Comroe, 1961), and this fact is illustrated by the specimen spirometer tracing (Fig. 1). This shows three normal 
breaths of $500 \mathrm{ml}$. tidal volume followed by a period of rapid shallow panting similar to that performed during measurements in the plethysmograph. At the start of panting there is a rapid increase in lung volume for a few breaths, after which lung volume stabilizes for a time though further fluctuations may occur if panting is prolonged. Though this point has been noted before, it has not been emphasized, and in the past there has sometimes been doubt about whether F.R.C. or T.G.V. has been used in the correction of airway conductance for lung volume.

The mean values of 3.98 and 4.61 litres for F.R.C. and T.G.V. respectively are a little high, but this probably represents the selection of fit young men as subjects, and the figures fall within the range of other series (Table II).

TABLE I1.-Present Lurig Volumes Compared with Values for Normal

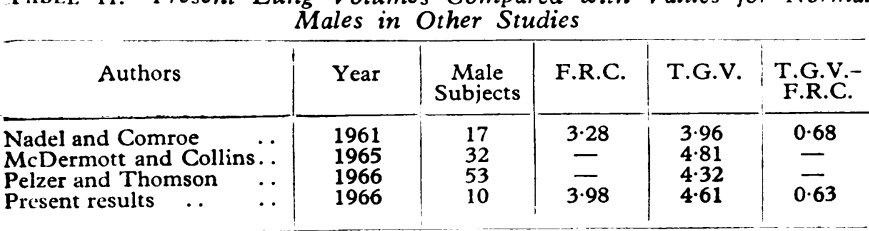

\section{Airway Resistance}

The mean C.A./T.G.V. of the 11 subjects was $0.205 \pm 0.033$ [S.D.] at rest before smoking, and $0.21 \pm 0.035$ at rest before atropine and smoking, showing that there was no overall difference in "bronchial tone" on the two occasions. These values agree well with those of 0.22 and 0.23 obtained from normal resting subjects in previous series (Nadel and Comroe, 1961 ; Pelzer and Thomson, 1966). However, there was some day-today variation within individuals, and anyone who showed a change in C.A./T.G.V. of more than $25 \%$ at rest was excluded from the trial.

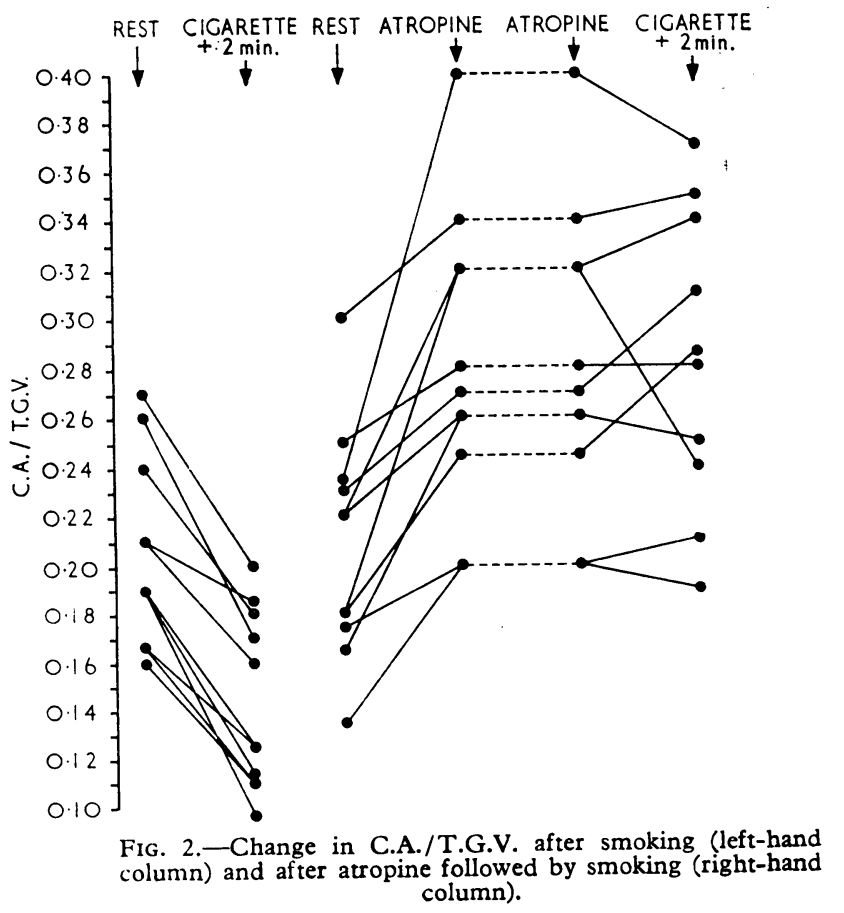

In all the subjects there was a fall in C.A./T.G.V. two minutes after finishing a cigarette, to a mean of $0.14 \pm 0.028$, which is a highly significant change $(\mathrm{P}<0.005$ by Student's $t$ test). There was considerable individual variation in this response, with a range of $-12 \%$ to $-53 \%$, but the average change of $-31 \%$ is very close to that found in an earlier study (Nadel and Comroe, 1961) (Fig. 2). The bronchoconstriction diminished rapidly, and in those subjects in whom it was followed serially C.A./T.G.V. had returned to resting values in 20 to 30 minutes.

After the injection of atropine there was a consistent rise in C.A./T.G.V., from a mean of $0.21 \pm 0.035$ to one of $0.28 \pm$ 0.63 , an average increase of $38 \%$, which confirmed previous findings of resting bronchial tone (Widdicombe et al., 1962). Inhalation of a cigarette after atropine failed to cause any consistent change in C.A./T.G.V., which showed only an insignificant mean fall of $0.6 \%$.

\section{Discussion}

These results confirm that the inhalation of cigarette smoke causes an increase in airway resistance, which is maximal within two or three minutes of smoking and usually declines to its resting value over about 20 minutes. It has been shown that this effect is unaltered by extraction of volatile substances from the smoke (Nadel and Comroe, 1961) or by varying the nicotine content of the cigarette smoked, and it has therefore been suggested that the tiny particles that constitute smoke are irritant to receptors in the airways. A similar response has been described in men and cats given chemically inert carbon particles to inhale, and the mechanism has been shown to be a vagal reflex, since in animals it can be blocked both by atropine and by vagal cooling, and since increased activity can be demonstrated in afferent vagal fibres (Widdicombe et al., 1962). Vagal reflexes are also the pathways for production of bronchoconstruction due to mechanical irritation of the larynx (Nadel and Widdicombe, 1962), or to inhalation of low concentrations of sulphur dioxide (Nadel et al., 1965). The prevention of bronchoconstriction by atropine in the present study therefore suggests that the same mechanism is involved, though the afferent side of the reflex arc has not been investigated.

It has generally been assumed that any increase in airway resistance is due to narrowing of the bronchi and bronchioles, but another possible explanation is that irritant particles might alter overall airway resistance by causing laryngeal obstruction through mucosal swelling or muscular contraction, particularly as extrathoracic resistance may comprise as much as $50 \%$ of total airway resistance during mouth breathing in normal subjects (Hyatt and Wilcox, 1961). However, it is difficult to see how atropine could prevent such a change except, possibly, by its drying action on the epithelium of the vocal cords. Moreover, in animal experiments, carbon particles inhaled through a tracheostomy, thus by-passing the larynx, still cause constriction of the lower airways, indicating that the latter are the site of at least part of the increased airway resistance.

The fall in resting airway resistance after atropine seen in normal subjects has been described before, and, like the prevention of a provoked rise in airway resistance, is generally attributed to blockade of vagal bronchomotor activity. This is certainly the most obvious and likely explanation, but there is some doubt on whether it is the only one, since the action of atropine in drying up bronchial secretions might be expected to cause some increase in the calibre of the airways. Differentiation of these mechanisms is difficult, but isoprenaline causes a comparable fall in airway resistance without affecting secretions significantly, which suggests that muscular relaxation could account for the major part of the dilator action of atropine.

\section{Summary}

Inhalation of cigarette smoke causes bronchoconstriction in both smokers and non-smokers.

This effect is almost certainly due to the irritant action of smoke particles. 
It can be blocked by atropine, suggesting that it is brought about by the vagus, probably through the action of the latter on bronchial smooth muscle.

I would like to thank Dr. J. C. Batten for his advice and encouragement, and Miss F. A. Boother for her frequent technical help.

This study was supported by a research grant from the Board of Governors, St. George's Hospital, London S.W.1.
REFERENCES

Briscoe, W. A., and DuBois, A. B. (1958). 7. clin. Invest., 37, 1279. DuBois, A. B., Botelho, S. Y., and Comroe, J. H. (1956). Ibid., 35, 327 Hyatt, R. E., and Wilcox, R.' E. (1961). F. appl. Physiol., 16, 326 McDermott, M., and Collins, M. M. (1965). Thorax, 20, 562 . Nadel, J. A., and Comroe, J. H., jun. (1961). \%. appl. Physiol. 16,713 .

Salem, H., Tamplin, B., and Tokiwa, Y. (1965). Ibid., 20, 164. - and Widdicombe, J. G.' (1962). Ibid., 17, 861.

Pelzer, A. M., and Thomson, M. L. (1966). Ibid., 21, 469.

Widdicombe, J. G., Kent, D. C., and Nadei, J. A. (1962). Ibid., 17, 613 Zamel, N., Youssef, H. H., and Prime, F. J. (1963). Lancet, $1,1237$.

\title{
Is the Woulfe Bottle an Efficient Humidifier for Oxygen?
}

\author{
BERNARD J. FREEDMAN,* M.B., B.S., M.R.C.P.
}

Brit. med. 7., 1967, 3, 277-279

Oxygen from cylinders is dry. The need for adequate humidity of inhaled gases in oxygen therapy is generally recognized. There is, however, no unanimity regarding the desirable level of humidity, nor regarding the best means of achieving it. Bubbling oxygen through water in a Woulfe bottle has been the most widely used method of humidifying oxygen since the early days of oxygen therapy. This method has been the object of adverse criticism. It has been alleged that it "does not result in adequate humidification" and that "this method should be abandoned" (Brit. med. F., 1964). Cadman (1961) was of similar opinion. The Woulfe bottle is a widely used apparatus for this purpose, and in many hospitals it is the only one. Before urging the widespread abandonment of a cheap, simple, and easily replaceable apparatus in favour of something complex and expensive, or of giving it up altogether, it seemed desirable to test the efficiency of the Woulfe bottle as a humidifier, since no record could be found of this having been previously done.

There are three questions to answer. What level of humidification does this method achieve within the range of working conditions likely to be encountered ? What level of humidification is desirable? Does this method meet chinical requirements? Experiments are described which give an answer to the first question, and an attempt is made to answer the second and third in the discussion which follows.

\section{Material and Methods}

Conventional bedside apparatus was used. Oxygen from a cylinder was bubbled through water in a Woulfe bottle and conveyed thence by $1.5 \mathrm{~m}$. ( $4 \mathrm{ft}$. 9 in.) of rubber tubing to a hair hygrometer which occupied the position of a face-mask. Oxygen flow-rates were measured with a bobbin flow-meter calibrated against a Parkinson-Cowan gas-meter. The Woulfe bottle measured $14 \mathrm{~cm}$. high and $5.8 \mathrm{~cm}$. internal diameter, and it was filled to a depth of $4.5 \mathrm{~cm}$. (about $160 \mathrm{ml}$.) with tapwater, the inlet tube reaching to $0.5 \mathrm{~cm}$. above the floor of the bottle. The tube conveying oxygen from the bottle was connected to an opening in one end of a transparent polyvinyl chloride bag. The hygrometer lay within the bag. It fitted fairly snugly so as to ensure adequate entry of humidified oxygen into its casing (Fig. 1). Oxygen left the bag through tubes inserted into the two distal corners. This prevented retrograde entry of ambient air. The hair hygrometer was calibrated against a wet-and-dry bulb whirling hygrometer.
Dry oxygen was passed through water in the Woulfe bottle at a constant rate. At intervals of two minutes or less the following were measured: (1) relative humidity in the bag, and (2) temperature of the water, of the gas in the bag reaching the hygrometer, and of the ambient air. Gas flow continued until stable readings were obtained. Duplicate experiments were

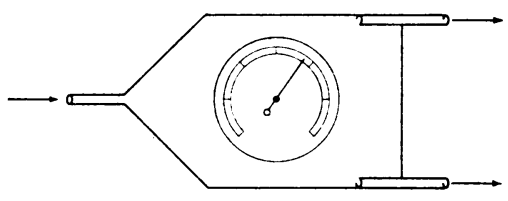

Fig. 1.-Humidified oxygen is passed through the plastic bag containing the hygrometer.

performed at flow-rates of 3,5, and 8 litres per minute in cool, temperate, and hot environments. The hot environment was in the hospital basement alongside the steam-pipes, the temperate was in the laboratory, and the cool was on a ward balcony. Day-to-day variations in weather conditions and in boiler temperatures rendered it impossible to achieve identical ambient temperatures in the experiments carried out within each of the three temperature ranges. Ambient temperatures were as follows :

$\begin{array}{lllllll}\text { Cool } & \ldots & \ldots & 11.0-13.4^{\circ} & \text { C. }\left(51.8-56.1^{\circ}\right. & \text { F. }) \\ \text { Temperate } & \ldots & 18.5-19.8^{\circ} & \text { C. }\left(65.3-67.6^{\circ}\right. & \text { F. }) \\ \text { Hot } \quad \ldots & \ldots & 27.6-31.6^{\circ} & \text { C. }\left(81.7-88.9^{\circ}\right. & \text { F. })\end{array}$

\section{Results}

After the oxygen was turned on, the humidity rose rapidly. Progressive cooling of the water then led to a corresponding fall in humidity. Eventually the water temperature and the relative humidity were steady. A high flow-rate and a high ambient temperature were associated with much cooling of the water (Table I), and a big drop in final humidity. For example, at $8 \mathrm{1} . / \mathrm{min}$. and $31.5^{\circ} \mathrm{C}$. $\left(88.7^{\circ} \mathrm{F}\right.$.), the water temperature fell as much as $11.6^{\circ} \mathrm{C}$. $\left(20^{\circ} \mathrm{F}\right.$.).

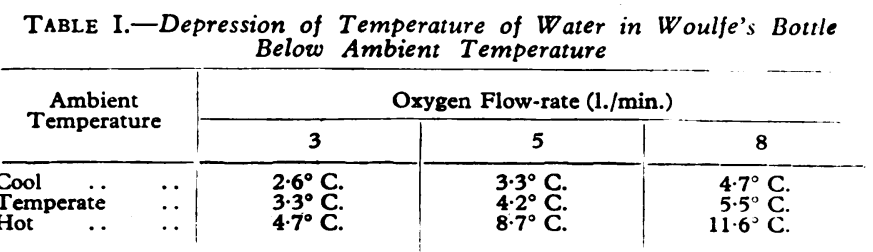

